\title{
Antiproliferative and Apoptotic Effects of Vanadyl Sulphate on H-Ras Transformed 5rp7 Cells
}

\author{
Hatice Mehtap Kutlu, Djanan Vejselova
}

Anadolu University, Faculty of Science, Department of Biology, 26470, Eskisehir, Turkey

Metal based drugs have successfully been used in the detection and treatment of a variety of diseases [1]. Despite the advantages in early diagnostic and treatment of cancer, there is essential to develop new alternative of drugs. A number of in vitro studies have revealed that vanadium shows its antitumor effects on various cell lines [2]. Moreover, it is shown that vanadium compounds may show cytotoxic effects through DNA cleavage and fragmentation, in vitro [3]. According to these studies, here in we aimed to investigate the cytotoxic and antiproliferative effect of vanadyl sulphate in vitro, also to detect the effect of this agent on H-Ras transformed 5RP7 cells ultrastructure.

For detecting the cytotoxic effects, the stock solution (in distilled water) of vanadyl sulphate, was further diluted with culture medium to $10,20,30,40,50,60,70,80,90$ and $100 \mu \mathrm{M}$ concentrations and applied on H-Ras 5RP7 cells ( $1 \times 10^{4}$ cells per well) for 24 hours. The plates were read on ELISA reader (ELX808) at wavelength of $540 \mathrm{~nm}(\mathrm{n}=3)$. From the Elisa reader results, the $50 \%$ inhibition concentration $\left(\mathrm{IC}_{50}\right)$ of the cells was determined to be $35 \mu \mathrm{M}$.

For ultrastructral changes, $H$-Ras $5 \mathrm{RP} 7$ cells incubated with $35 \mu \mathrm{M}$ for 24 hours were fixed with $2,5 \%$ glutaraldehyde (in 0,1M phosphate buffer, $\mathrm{pH}$ 7.4) and left in buffer overnight at $+4{ }^{\circ} \mathrm{C}$. After being embedded in agar and post fixed in \%2 osmium tetroxide, the cells were dehydrated in graded ethanol $(70 \%, 90 \%, 96 \%$ and 100\%). Dehydrated cells were embedded in EPON 812 epoxy (Germany) and sectioned on ultramicrotome (LEICA UC6, Germany). Structural and ultrastructural changes of these cells were observed on transmission electron microscope (TEM) and photographed.

Our results demonstrated that vanadyl sulphate showed high sitotoxicity on H-Ras transformed 5RP7 cells in low concentrations. Also, in our results it is shown the structure and ultrastructural changes like membrane blebbing and nuclear fragmentation as apoptotic sparks on H-Ras transformed 5RP7 cells caused by vanadyl sulphate via transmission electron microscopy (TEM). According to these sparks, vanadyl sulphate has induced apoptosis in H-Ras transformed 5RP7 cells. Consequently, we can say that vanadyl sulphate with its effects on H-Ras transformed 5RP7 cells may expose well inspiration for designing of pharmaceutical products helpful in cancer treatment.

\section{References:}

[1] B Thati, European Journal of Pharmacology 602 (2009), 203-214.

[2] J Kieler, A Gromek, NI Nissen, Acta Chir Scand 343 (1965), 154-164.

[3] HJ Thompson, DN Chasteen, L Neeker, Carcinogenesis 5 (1984), 849-851. 


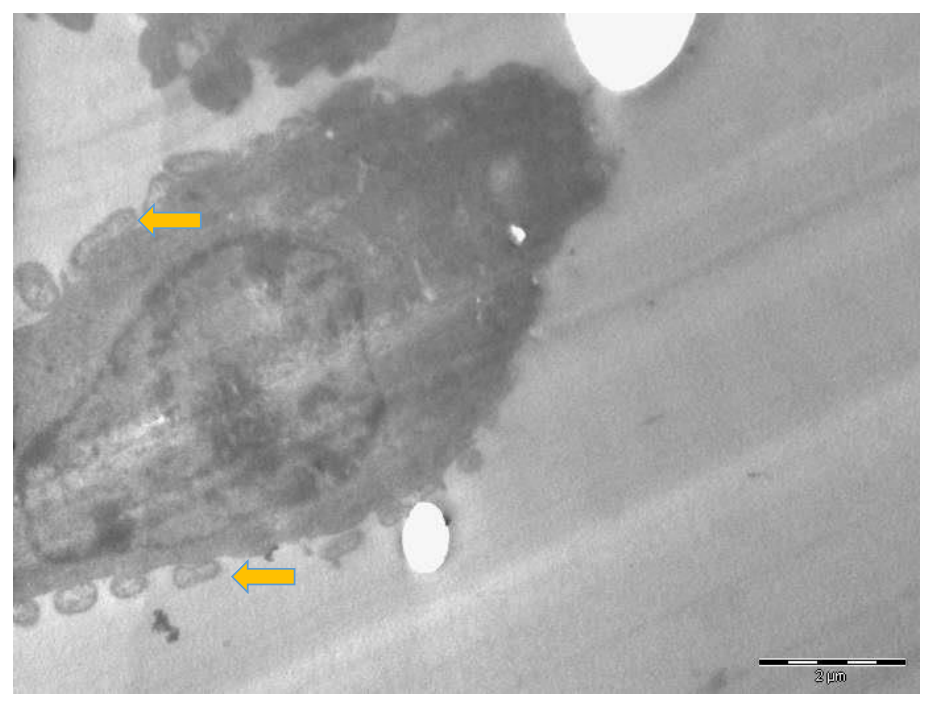

Figure 1. Transmission electron micrograph of $5 \mathrm{rp} 7$ cell treated with $\mathrm{IC}_{50}$ value of vanadyl sulphate for 24 hours $(10 \mathrm{kx}) . \quad$ : Membrane blebbings.

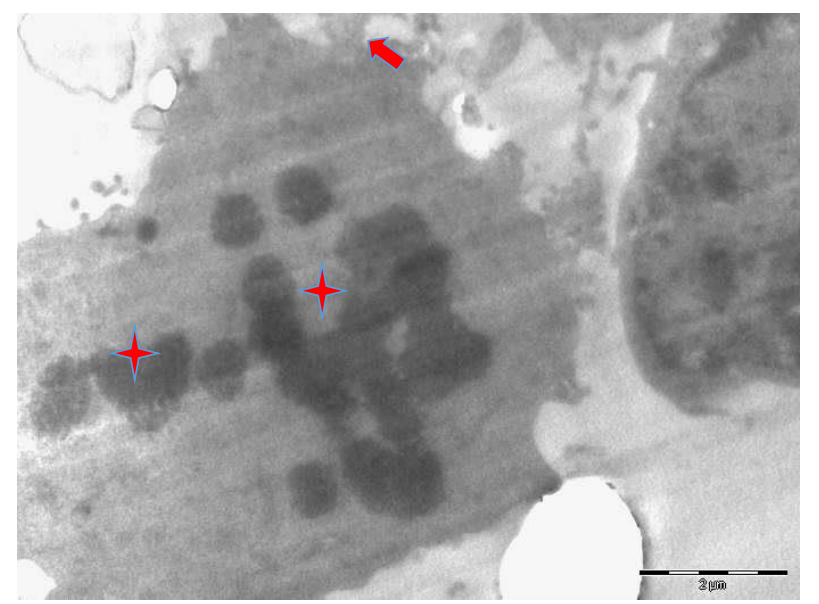

Figure 2. Transmission electron micrograph of $5 \mathrm{rp} 7$ cell treated with $\mathrm{IC}_{50}$ value of vanadyl sulphate for 24 hours $(10 \mathrm{kx}) .+$ : Nuclear fragmentations; $\mathbf{W}$ Membrane blebbing 